\title{
Knowledge Creation Process and Firms' Innovation Performance: Mediating Effect of Organizational Learning
}

\author{
Sarra BERRAIES (Corresponding author) \\ Associate Professor, ISIGK, University of Kairouan, Tunisia \\ E-mail: sarraberraies610@yahoo.fr \\ Mehrez CHAHER \\ Professor, ISGT, University of Tunis, Tunisia \\ E-mail: chahermehrez@yahoo.fr
}

Doi:10.5296/ijhrs.v4i1.5517

URL: http://dx.doi.org/10.5296/ijhrs.v4i1.5517

\begin{abstract}
On the basis of the Nonaka and Takeuchi (1995)'s study, this paper examines the effects of knowledge creation process on firm's innovation performance and the mediating role of organizational learning in this relationship. Conceptually, we develop a research model summarizing the relationships between these variables. This model was tested within 214 companies belonging to the information technology and communication (ICT) sector. Results highlight the role of organizational learning as a partial mediator in the relationship between the knowledge creation process and innovation performance. Findings identify also the importance of tacit-linked activities namely socialization, internalization and externalization for innovation performance of the Tunisian ICT companies.
\end{abstract}

Keywords: Knowledge creation process, organizational learning, innovation performance.

\section{Introduction}

Today's economic environment is characterized by a high degree of turbulence due particularly to rapid technological changes and increased competition between companies. In such context, firms' survival is based on their capacity to successfully adapt their strategies in response to the environment's changes. Along this line, continuous innovation is the key to meet changing customer needs and sustain competitive advantage (Drucker, 1985; Porter, 1986). Hence, in order to develop their innovation capabilities, companies have to invest more resources to constantly seek, create and exploit new knowledge that may allow them to 


\section{MInstitute ${ }^{\text {Mat }}$}

build new ideas of products or services, production technology or procedure, marketing or organizational practices or either managerial strategies (Gunday et al., 2009; Škerlavaj et al., 2010). Indeed, as stated by Drucker (1993), in today's knowledge society, the main challenge for companies is to raise knowledge productivity. Furthermore, according to Wang and Wang (2012), the sharing of both explicit and tacit knowledge within companies is intrinsically associated to their innovation speed and quality. Drucker (1993) pointed out in addition that to innovate, companies have to generate new knowledge and to abandon obsolete ones.

In this perspective, the relationship between knowledge creation and firm's innovation has been the focus of a numerous theoretical and empirical studies. The majority of these researches concluded that knowledge creation is a fundamental predictor of innovation (Garcia-Morales et al., 2008; Miller and Morris, 1999; Nonaka, 1991; Nonaka and Takeuchi, 1995; Nonaka et al., 2006; Sankowska, 2013; Wang and Wang, 2012). In particular, Nonaka (1991) and Nonaka and Takeuchi (1995) claimed that knowledge creating companies are the most successful companies. Through their investigations within industrial Japanese companies, they configured a knowledge conversion theory that explains how these companies achieve knowledge creation. The cornestore of Nonaka (1991) and Nonaka and Takeuchi (1995)'s theory is the SECI model, which is based on four modes of knowledge conversion: Socialization, Externalization, Combination and Internalization. These authors concluded that success secret of Japanese companies lies in their capacities to create and exploit new knowledge continuously.

In this paper, we focus on the KCP by referring to the SECI model, which is recognized as the main important contribution in the domain of knowledge management. Literature review reveals that researchers who examined the relationship between the four modes of knowledge creation integrating the SECI model and firms' innovation found controversial empirical results. For instance, within Chinese context, Binbin et al. (2012) concluded that the four modes of knowledge conversion contribute to innovation in Chinese context. Within Egyptian context, Refaey (2002) found that only externalization and combination are related to firm's innovation. Schulze and Hoegl (2008) suggested that externalization is negatively linked to novelty of product ideas though an empirical study they conducted within 33 firms from Germany, Austria and Switzerland. Empirical results differ in particular from one context to another. It would be hence interesting to examine the relationship between the four modes of knowledge creation and firm's innovation in the case of the Tunisian context.

Moreover, despite there are many researches focusing on the impact of KCP on innovation, few empirical studies have been realized to sufficiently examine how concretely $\mathrm{KCP}$ contributes to innovation and to determine in particular mediating variables in relation to the knowledge creation that could improve innovation.

As demonstrated by Ramirez and Kumpikaite (2012), creation, transfer and application of knowledge have a positive effect on organizational learning (OL) which in turn contributes to business innovation. Cohendet et al. (2003) suggested also that "the cognitive architecture of knowledge in the companies (how knowledge is constructed, stored, exchanged, transferred, rebuilt) influences the OL process, which is in turn retroacts on firm's innovative process". Thus, OL (related to an organization's behavioral and cognitive changes) (Huber, 1991) may be a mediator variable between KCP and innovation performance. 
The aim of this paper is to add substance to the current theory by testing the relationships between KCP, OL and innovation performance within the context of the Tunisian Information and Communication technologies (ICT) companies. In particular, a major purpose of this research was to test the effect of KCP in the perspective of SECI model on firm's innovation performance and the mediating effect of OL between these variables.

This paper is organized as follows. First, we review the existent literature on the topic of knowledge creation process (KCP), innovation performance and OL. Then, we develop a research model that emphasizes the impact of KCP on innovation and the mediating effect of OL in this relationship and we formulate a series of hypotheses. Next, we identify the methodology and the results of our empirical study. As a final point, we analyze the results obtained and we provide in this line a series of managerial implications, the main limitations and the future perspectives of this research.

\section{Literature background}

\subsection{Knowledge creation process $(K C P)$}

In today's knowledge-based economy, knowledge is recognized as a primary ingredient for sustaining companies' survival (Colombelli et al., 2013) and competitiveness (Nonaka et al., 2006). Sveiby (2000) pointed out pertinently that the wealth of the firms lies in their ability to benefit from knowledge. The same idea was advocated by Nonaka and Takeuchi (1995) who emphasized the role of KCP as the key success factor of companies.

The theoretical framework on the basis of which we have chosen to analyze the knowledge creation within the company is based on Nonaka (1991) and Nonaka and Takeuchi (1995)'s theory. In fact, Nonaka (1991) noted that the innovation capacity of Japanese companies such as Honda, Canon, Matsushita and Sharp is based on "their unique approach to manage the creation of new knowledge". In the extension of Nonaka (1991)'s work and through their book 'Knowledge-Creating Company', Nonaka and Takeuchi (1995) claimed that knowledge can be created and shared through an interactive process including socialization, externalization, combination and internalization (SECI). In this process, interactions take place in two levels: an interaction between actors that amplify knowledge from individual to groups and then to organization and an interaction between two type of knowledge (tacit and explicit).

The first stage of this process is socialization which refers to the creation of new tacit knowledge through an implied sharing of tacit knowledge between individuals. Tacit knowledge can be shared and created via social interaction between apprentices and experts by observation, imitation and practice (Nonaka, 1991). Companies can absorb tacit knowledge through interactions with customers or suppliers (Nonaka et al., 2000). This mode of knowledge creation can also occur during brainstorming camps in which creative discussions and sharing experiences take place to resolve problems and to generate new ideas (Nonaka and Takeuchi, 1995).

The second stage of SECI model is externalization which refers to the process of conversion of tacit knowledge into explicit knowledge. In this perspective, knowledge climbed another ontological level: it is transferred from the individual to the group level. The use of 
metaphors, analogies and creative dialogue can help to articulate tacit ideas and create new explicit concepts of products (Nonaka and Takeuchi, 1995).

The third stage relates to the combination of explicit knowledge that generates new explicit knowledge shared among members of the organization. Nonaka (1991) gives the example of a comptroller of a company who synthesizes the collected explicit knowledge into a financial report. Combination may occur through meetings, conversations, documents and computerized communications networks (Nonaka and Takeuchi, 1995).

Finally, the fourth stage is the internalization which refers to the conversion of explicit organizational knowledge into tacit knowledge by individuals. In this step, individuals acquire organizational explicit knowledge and converted it to a new tacit knowledge by putting it into a practice (Nonaka and Takeuchi, 1995). Training programs, simulations, experimentations, reading and using documents about work tasks and job rotation are tools for internalizing of knowledge (Nonaka and al., 2000). By using procedural manual which lists the explicit experiences of other employees, individual can converted these explicit knowledge into tacit knowledge once assimilated. After internalization, a new spiral of knowledge creation is initiated.

The SECI model is recognized as the most robust model in the domain of knowledge management. It is presented by Nonaka and Takeuchi (1995) as a 'universal' model. In this perspective, some researchers challenge the universal applicability of this model (Glisby and Holden, 2003, Hong, 2010; Hutching and Weir, 2005). Hong (2010) claimed that Nonaka and Takeuchi (1995)'s theory is a product of Japanese environment. Glisby and Holden (2003) pointed out that all modes of knowledge creation are specific to a Japanese culture and not easily transposed to another context. They suggested that SECI model may be a reference for companies in another's contexts for initiating change in the perspective of Japanese culture values. Hutching and Weir (2005) questioned also the cultural limits of universal validity of SECI model. They reported that despite cultural differences compared to the Japanese context, this model can be applied efficiently in Arab context.

\subsection{The effect of KCP on innovation performance}

It is widely accepted in the literature that the ability of companies to innovate is a critical factor for their survival and competitiveness (Drucker, 1985; Porter, 1986). In this perspective, studies have identified several enablers of innovation. In particular, numerous researches indicate that a firm's capacity to absorb and to use knowledge is the main driving force for innovation (Nonaka and Takeuchi, 1995; Popadiuk and Choo; 2006, Ramirez and Kumpikaite, 2012; Sankowska, 2013; Svetina and Prodan, 2008).

In fact, innovation refers to "the successful implementation of creative ideas, tasks or procedures" (Cummings and Kiesler, 2003). These creative ideas are generated via social interactions that enable sharing and creation of knowledge. Afuah (1998) define also innovation as a new knowledge incorporated into products, processes or services. According to these definitions, knowledge is understood as an essential component of innovation. Svetina and Prodan (2008) suggested that the extent of use of knowledge, which has been acquired from internal or external sources, has a positive influence on firm's innovative 
performance. In addition, Hall and Andriani (2003) argued that the amount of new knowledge acquired and applied determines the degree of innovation. Zohoori et al. (2013) underlined the effect of both tacit and explicit knowledge on speed and quality of innovation. In addition, Kluge et al., (2001) pointed out the significant impact of KCP speed on innovation success.

Based on our study, we may now examine the role of the four modes of knowledge creation in the perspective of the SECI model on innovation. Nonaka and Takeuchi (1995) emphasized that the interactive creation of new knowledge, their dissemination and application throughout the organization are catalysts of firm's innovation. Innovation is founded on continuous KCP that enables recognition of opportunities and generation of new ideas (Popadiuk and Choo, 2006). In this connection, the novelty of an idea depends on whether we create and use tacit knowledge or explicit knowledge. Indeed, through socialization and externalization, tacit knowledge, which is personal and hard to externalize, is generated and communicated to others. These two modes of knowledge creation are on the basis of creating of new concepts and thus of exploratory innovation (Popadiuk and Choo, 2006). Schulze and Hoegl (2008) suggested that socialization is positively linked to the novelty of product ideas. According to these authors, "informal and face-to-face interaction of individuals, 'with varied perspectives', give rise to novel product idea" (Schulze and Hoegl, 2008). This interaction enables variety of perspectives and may occur between employees inside the organization. It also may happens or outside the organization, especially with consumers and may lead to creation of new products that meet their needs. In addition, in contrast to Popadiuk and Choo (2006)' research, Schulze and Hoegl (2008) demonstrated that externalization, which occurs in formal meetings and by planned approaches, is negatively related to the novelty of product idea.

Popadiuk and Choo (2006) underlined also the role of combination and internalization processes on exploitative innovation. Schulze and Hoegl (2008), meanwhile, stated that since combination represents a pure re-combination of existing explicit knowledge, it is associated with incremental innovation. Furthermore, according to these authors, internalization has a positive effect on the novelty of product idea. They argued that internalization "enhances the absorption of existing knowledge, which in turn enables individuals to create new visceral knowledge and hence novel ideas" (Schulze and Hoegl, 2008).

Moreover, Binbin et al. (2012) concluded that each dimension of SECI model is an important success factor of innovation in Chinese context. Refaey (2002), meanwhile, stated that only combination and externalization have a positive effect on innovation in the case of Egyptian context.

Thus, on the basis of theoretical analysis presented above, we pose the following hypothesis: Hypothesis 1: KCP has a positive effect on innovation performance.

\subsection{OL as mediator between KCP and innovation performance}

OL has been the focus of considerable researches. A review of the academic literature on this topic shows basically two main approaches to define OL: a behavioral approach and a cognitive approach. The followers of behavioral approach conceptualized learning as the result of the interlinking of a stimulus and a response that changes the behavior (Cyert and 
March, 1992; March and Olsen, 1976). At the organizational level, learning characterizes in particular the relationship between a company and its environment. It occurs when face to environmental changes (stimulus), the organization adapts its behaviors (response) relying on its routines (Levitt and March 1988). According to the cognitive approach, OL is defined as a modification in the state of organizational knowledge and schemas of interpretation which induces organizational change (Argyris and Schön, 1998). A major contribution to the cognitive approach is represented by the work of Argyris and Schon (2001). These authors identified two types of learning: single-loop learning and double-loop learning. According to these authors, single-loop learning or 'adaptive learning' refers to a minor adaptation of behaviors which focuses on correction of errors without reflecting on the relevance of current strategies and norms modulating the actions. This type of learning fits into the behavioral theory. Argyris and Schön (1978) suggested that the double-loop learning or the 'generative learning' induces a more profound change and occurs when routines are challenged and new mental models are generated. From both cognitive and behavioral perspective, Huber (1991) perceived OL as a change in the repertory of an organization's potential behaviors resulting from the information's acquisition, distribution, interpretation and storage. OL is understood in this approach as a result of cognitive and behavioral changes. Our study is in line with this integrative approach. Indeed, we base our analysis of knowledge creation and OL on the SECI model developed by Nonaka and Takeuchi (1995), which "combines cognitive and behavioral dimensions of learning" (Bootz, 2001). Socialization and internalization relate to a behavioral learning while combination and externalization are associated with a cognitive learning (Bootz, 2001).

In view of the above, we understand the concept of OL as both behavioral and cognitive changes. In the perspective of Huber (1991), we perceived OL as a change in organization's behaviors which results according to our study from the process of conversion of knowledge as defined in the SECI model of Nonaka and Takeuchi (1995). Indeed, we postulate that we cannot talk about learning unless if a created and shared knowledge is converted into new actions or else results in a development of individual or organizational skills within the company.

In the line of previous researches, we suggest in this paper that $\mathrm{KCP}$ is a foundation for achieving innovation performance. In building a conceptual model linking KCP and innovation performance, we also reflected on the integration of mediating variables which can help to clarify this link. In this perspective, we choose to examine the role of OL as a mediator between KCP and innovation performance. For this purpose, we analyzed first the link between KCP and OL. We examined then the effect of OL on innovation performance. Finally, we concluded that OL may be a mediating variable between KCP and innovation performance.

\subsubsection{Effect of $\mathrm{KCP}$ on $\mathrm{OL}$}

The link between KCP and OL had been established by a wide body of conceptual and empirical literature (Dermol, 2013; Ramírez et al., 2011; Ramírez and Kumpikaite, 2012). Indeed, "OL and organizational knowledge creation are mutually dependant" (Lyles, 2014). 
In this perspective, Malerba (1992) emphasized that learning depends on the exploitation of both internal and external sources of knowledge. Costanzo and Tzoumpa (2008) pointed out the critical role of middle managers in facilitating knowledge transfer and as key factors for OL. These authors suggested also that organization's teams "constitute an important organizational context where OL takes place" through knowledge creation and transfer resulting from the interaction of their members (Costanzo and Tzoumpa, 2008).

Through an empirical study conducted within service companies located in Slovenia, Dermol (2013) provided evidence also that "in an organization in which activities related to knowledge creation are carried out more often, changes in cognition and behaviour appear". Nonaka and Takeuchi (1995) claimed that the processes of socialization, externalization, combination and internalization characterize learning organizations.

Within Spanish context, Ramírez et al. (2011) demonstrated the major effect of two modes of knowledge creation of SECI model namely socialization and internalization, on OL. In this line, Fillol (2006) attests to the existence of a close link between socialization which assures interpersonal exchanges and OL. The same idea was advocated by Al-adaileh et al. (2012) who argued that socialization "has the potential to influence learning process on the three levels of learning" (individual, groups and organization). Through socialization, sharing experiences between employees can lead to changes in organization's behavior.

Then, Al-adaileh et al. (2012) considered that externalization "might impact team learning through the effect of individual learning on team learning and accordingly on $O L$ ". It is related to generative learning (Bootz, 2001; Yoon et al., 2009). This mode of knowledge conversation helps to explicit tacit knowledge and to share and integrate the new knowledge generated into the organization's knowledge base. This process creates thus new organizational mental models that modulate organization's behavior (Nonaka and Takeuchi 1995).

Moreover, Al-adaileh et al. (2012) indicated that combination has a positive impact on OL. According to these authors, combination refers to both team learning and OL. Bootz (2001) suggested also that combination is also closely related to generative learning. This dimension of SECI model enriches the organizational memory of the company which plays an important role in the development of OL (Van Der Bent et al., 1999).

Finally, internalization is fundamentally linked to OL (Al-adaileh et al., 2012; Nonaka et al., 1994; Ramírez et al., 2011). In this stage, individual puts into a practice organizational knowledge and integrates it until in to concrete actions. According to Yoon et al. (2009), this mode of knowledge conversation is associated with reflective learning process which is the "foundation for suitable changes and organizational transformation".

Accordingly, we propose the following hypothesis:

$\mathrm{H} 2$. KCP has a positive effect on OL.

\subsubsection{Effect of OL on innovation performance}

A review of the literature shows a broad consensus that the OL is a key factor of company's innovation (Baker and Sinkula, 1999; Lundvall, 1992; Nonaka and Takeuchi, 1995). Nonaka and Takeuchi (1995) suggested that knowledge creating companies which are characterized 
by learning culture continuously innovate. Lundvall (1992) argued that innovation is strongly associated with "an ongoing processes of learning searching and exploring which result in new products, new techniques, new forms of organization and new markets".

Indeed, OL affects the generation of innovative ideas and is significantly related to organizational creativity (Damanpour, 1996). Baker and Sinkula (1999) claimed that OL enables organizations to design new products or services that meet consumer's needs and to introduce them in to the market successfully. Svetina and Prodan (2009) pointed out also that "internal learning and interactive learning with firms and institutions in a wider business environment mutually reinforce each other and bring optimal results in terms of innovation performance".

On the basis of an empirical study within European companies, Ramírez and Kumpikaite (2012) concluded that OL is correlated to business innovation. The same finding was found by Jimènez-Jimènez and Sanz-Valle (2011) in Spanish context and by Tohidi et al. (2012) in Iranian context.

Accordingly, we propose the following hypothesis:

H3. OL has a positive effect on innovation performance.

\subsubsection{Mediating effect of OL between KCP and innovation performance}

As we stated above, several academics emphasized the role of KCP as a driver for effective OL which contributes to innovation performance. In this line, Cohendet et al. (2003) highlight that the company's knowledge base influences the OL, which in turn is a critical factor for innovation. These authors suggest us that $\mathrm{OL}$ is a mediator between KCP and innovation.

To test the role that OL may play in the KCP-innovation performance link, we pose the following hypothesis:

$\mathrm{H} 4$. OL mediates the relationship between $\mathrm{KCP}$ and innovation performance.

\subsection{Research model}

Based on the theoretical debates synthesized, we developed a research model (Figure 1). This model highlights that $\mathrm{KCP}$, including socialization, externalization, combination and internalization have a positive direct impact on OL which in turn affects innovation. The research model was tested empirically in the case of Tunisian ICT sector.

\section{[Insert Figure 1 here]}

\section{Empirical study}

\subsection{Research Methodology}

In order to test our research hypothesis, we adopted a quantitative research approach by administrating a questionnaire in paper and electronic form to a sample of Tunisian companies belonging to the ICT sector. A quota sampling method was used to define survey 
participants. In this perspective, we choose companies on the basis of three main criteria namely their age, size and following the branches of the ICT sector to which they belong.

The final questionnaire including items measuring our research variables was pretested and then sent to 306 managerial staff of Tunisian ICT companies. According to these criteria, the number of selected companies includes 306 companies which are older than 3 years and employing at least 10 individuals. Finally, we received 214 valid questionnaires, representing a responsiveness rate of $69 \%$.

The range age of these companies is predominantly between 5 and 10 years (43.92\%). Moreover, the firms selected are characterized by their small size. $65 \%$ of them employ fewer than 50 employees. Moreover, nearly $90 \%$ of respondents have more than 5 years experience in the company in which they work. The majority of them are males (74\%).

Each variable of this research was measured through existing scales developed by previous studies and assessed with statements using a five point Likert-type scales ranging from strongly disagree to strongly agree.

To capture the extent of knowledge creation, a 19-item scale was adapted from Nonaka et al. (2000) for this study. This scale has multi-item subscales related to four dimensions: (1) socialization, (2) externalization, (3) combination and (4) internalization.

For innovation, we use 5-item scale developed by Svetina and Prodan (2009). Mangers were asked to specify if "their company had registered patents in the last 3 years and had introduced or adopted any major changes to their products processes, organization of production and organization of sales and distribution" (Svetina and Prodan, 2009). OL which is defined in this study as behavioral and cognitive changes was measured through Škerlavaj et al., (2010)'s 14-item scale.

\subsection{Measurement model evaluation}

In first step, via SPSS 18.0 statistical program, data were subject to an exploratory factor analysis (EFA). Indeed, we used principal component analysis with varimax rotation to test the dimensionality of each measuring scale of the latent variables. On this basis, some items with factor loading values less than 0.5 were eliminated. We calculated Cronbach's alpha to test internal consistency for each measuring scales. Results indicate satisfactory internal reliability (Table 1) by showing that the values of this index are ranged from 0.728 to 0.990 and thus are above 0.70 as recommended by Fornell and Larker (1981). The exploratory analysis showed that OL and innovation performance are unidimensional constructs while $\mathrm{KCP}$ is multidimensional and comprises 4 dimensions namely socialization, externalization, combination and internalization.

In next step, confirmatory factor analysis via the AMOS software was also performed in order to evaluate the measurement models. First, since SEM is sensitive to non-normality, normality of data distributions was assessed through Skewness ( $<3$ in absolute value) and Kurtosis statistics ( $<8$ in absolute value) as advocated by Roussel et al. (2002). Then, we examined fit measurement models provided by AMOS which reveals that these models fit well with the data. For KCP, we performed a second-order model. Along this line, fit indices for this model are satisfactory and are better than the first order model.

Internal consistency of each scale was then confirmed by Jöreskog Rhôs (>0.7) (Fornell and 
Larcker, 1981) (Table 1). 2014, Vol. 4, No. 1

\section{[Insert Table 1 here]}

Then, convergent validity that establish how well the items measured their related variables was tested through rhô of convergent validity $(\rho v c)$ index which must be greater than 0.5 (Fornell and Larcker, 1981). Results (Table 1) indicate that convergent validity is assessed for all constructs. For this purpose, we also examined the loading paths of the items which exceeded 0.5 as recommended by Hair et al. (1998).

Finally, discriminant validity that establish how well the items related to different subscales measure different constructs, was assessed by verifying if the rhô of convergent validity of each construct is larger than its correlations to other constructs (Fornell and Larcker, 1981). Findings show that discriminant validity is established for all measuring scales.

\subsection{Results}

With AMOS, we performed a structural equation modeling (SEM) in order to test causal relationships between variables and mediating effect in our research model. In particular, Maximum Likelihood method was applied. We tested mediating effect of OL through Baron and Kenny (1986)'s method. According to these authors, we must verify the significant links between the independent variable (KCP) and the mediating variable (learning) and also between the mediating variable (OL) and the dependant variable (innovation performance). Then, mediation is established if the effect of the independent variable on the dependant variable is reduced by the mediating variable. If the direct effect becomes insignificant, mediating effect is therefore complete. According to MacKinnon et al. (1995), we calculated the indirect effect as $\mathrm{a} \times \mathrm{b}$ (where ' $\mathrm{a}$ ' is the standardized regression coefficient between KCP and OL and ' $b$ ' is the standardized regression coefficient between OL and innovation performance). The Sobel test is finally used to test the significance of the mediating effects.

For additional analysis, we tested two models. In the first model, KCP is evaluated as a second order variable comprising the four modes of knowledge creation. In the second model, KCP was divided into socialization, externalization, combination and internalization.

Full structural models fit was verified by using the most useful fit indices recommended by Bentler and $\mathrm{Hu}$ (1999) and Chin and Todd (1995). Building on this, we ensured that the Chi-Square value per degrees of freedom ( $\left.\chi^{2} / \mathrm{df}\right)$ did not exceeded 3, the Goodness-of-fit index $(G F I)$ value is greater than 0.9, the Comparative Fit Index (CFI) value exceeded 0.95 and that the Root Mean Square Error of Approximation (RMSEA) value did not exceeded 0.06. The Normed Fit Index (NFI) is larger than 0.95. Findings show that the model has an excellent adjustment to the data (Table 3).

\section{[Insert Table 2 here]}

Next, in order to test our research hypothesis, standard regression coefficients $(\beta)$, critical 
ratio (C.R.) and level of significance (P) were used. A relationship between two variables is significant if the C.R. value is greater than 1.96 in absolute value and $\mathrm{P}$ is lesser than 5\%.

Results (Table 4) shows a significant direct relationship between KCP and innovation $(\beta=0.579, \mathrm{p}<0.001)$. Hypothesis 1 is therefore confirmed. In particular, as shown in table 3, results indicate that socialization $(\beta=0.317, p<0.001)$, externalization $(\beta=0.243, p<0.001)$ and internalization $(\beta=0.240, p<0.01)$ have a positive and significant influence on innovation. However, combination was not significantly linked to innovation $(\beta=0.017, p>0.05)$.

\section{[Insert Table 3 here]}

Findings (Table 4) reveal next that KCP has a positive effect on OL $(\beta=0.381, p<0.001)$. Hence, hypothesis 2 is confirmed. Especially, OL is predicted by socialization $(\beta=0.408$, $\mathrm{p}<0.001)$, externalization $(\beta=0.337, \quad \mathrm{p}<0.001)$, combination $(\beta=0.178, \quad \mathrm{p}<0.05)$ and internalization $(\beta=0.262, \mathrm{p}<0.001)$.

OL is also significantly and positively related to innovation $(\beta=0.274, p<0.001)$, which provides support for hypothesis 3 .

To test mediating effect in our research model, we examined conditions advocated by Baron and Kenny (1986). In this research, we predicted that OL may be a mediator between KCP and innovation performance. Results suggest that OL mediate the relationship between these variables. Indeed, findings reveal that when OL was entered in the model, the previously link between KCP and innovation performance $(\beta=0.579)$ decreased but stilled significant $\left(\beta^{\prime}=0.066^{*}\right)$. Thus, OL as a mediator reduced the total effect of independent variable (KCP) on the dependent variable (innovation performance) by the total of the indirect effect. In this case, the mediating effect operated by OL in the model tested is partial. Finally, Sobel test was used and confirmed the significance of the mediating effects $(Z=2.783, p<0.01)$. Hypothese 4 is hence partially supported.

\section{[Insert Figure 2 here]}

\section{Discussion and conclusion}

The Results derived from SEM analysis show that all research's hypotheses are supported. In fact, on the basis of the most popular theory in knowledge management namely the SECI model, the aim of this paper was first to identify the role that $\mathrm{KCP}$, including socialization, externalization, combination and internalization, plays in innovation performance. This study provides further empirical assessment to assumed significant direct relationship between these variables. This result is in accordance with previous researches (Binbin et al., 2012; Nonaka and Takeuchi, 1995; Popadiuk and Choo; 2006; Ramirez and Kumpikaite, 2012). As emphasized by Nonaka and Takeuchi (1995), KCP is a catalyst for firms' innovation. Knowledge creation is thus highlighted as a key factor for innovation not only in the industrial sector in the line of the work of Nonaka and Takeuchi (1995) but also within ICT sector and in a context completely different from the Japanese context in which was designed the SECI model. This is particularly important because as we stated above, some researchers 
challenged the universal applicability of this model especially in Arab culture (Glisby and Holden, 2003, Hong, 2010; Hutching and Weir, 2005).

In particular, the dimension of the SECI model that produces and allows sharing of tacit knowledge namely socialization has the strongest influence on innovation performance. The importance of the creation and sharing of tacit knowledge in improving innovation performance is thus confirmed. This result is in line in particular with Hutchings and Weir (2005) who suggested that socialization happens quite effectively in Arab context. In addition, externalization has also a positive and significant impact on innovation performance. This finding corroborates in particular the works of Popadiuk and Choo (2006) who claimed that socialization and externalization are two key processes that allow generation and sharing of tacit knowledge and have a significant impact on creating of new concepts and thus of exploratory innovation. Results confirm also that internalization is positively correlated to firms' innovation performance. As stated by Schulze and Hoegl (2008), through applying explicit existing knowledge in practice, innovators can generate new ideas and can therefore initiate exploratory innovation. In contrast, the process of combination which refers to the recombination of purely explicit knowledge does not have a significant impact on firms' innovation performance. Along this line, Schulze and Hoegl (2008) pointed out that "recombining existing knowledge will not lead to the expected output of novel ideas".

Hence, results confirm that tacit knowledge plays a greater role than explicit knowledge in innovation (Nonaka and Takeuchi, 1995; Hall and Adriani, 2003). Innovation in ICT Tunisian sector depends therefore on tacit linked activities.

In addition, as expected our research reveals that $\mathrm{KCP}$ has a positive and significant effect on OL. The knowledge creation is thus a fundamental aspect of OL. This finding is consistent with the studies of Al-adaileh et al. (2012), Nonaka and Takeuchi (1995), Ramírez et al. (2011) and Ramirez and Kumpikaite (2012). The central role of the SECI model established by Nonaka and Takeuchi (1995) as a driver of improving OL is thus confirmed empirically. Ad advocated by these authors, the dynamics of knowledge creation characterizes learning organizations.

Particularly, results provide clear evidence regarding the importance of the process of socialization as a key factor for enhancing OL. Indeed, this mode of knowledge creation has the major effect on OL. This finding corroborates the works of Al-adaileh et al. (2012), Fillol (2006) and Ramírez et al., (2011). Through the interpersonal exchanges between employees within socialization, OL results from transfer of individual tacit knowledge which is hard to formalize to the benefit of other organization's members.

Moreover, our research indicates that externalization is also significantly related to OL. This finding thus contradicts with the findings of Al-adaileh et al. (2012) suggesting that externalization hasn't significant impact on OL strategy within Algerian Business organizations. In fact, as we analyzed above, externalization generates new organizational mental models and thus new cognitive changes that modulate organization's behavior (Nonaka and Takeuchi 1995, Yoon et al., 2009). It is related to a generative learning (Bootz, 2001; Yoon et al., 2009). This mode of knowledge conversation helps to explicit tacit knowledge and to share and integrate the new knowledge generated into the organization's knowledge base. 
Our study presents also strong relationship between combination and OL. This result confirms the works of Al-adaileh et al. (2012) suggesting that combination is significantly related to learning organization strategy. This mode of creation process enriches the organizational memory which represents a key factor in enhancing OL (Van Der Bent et al., 1999).

Our research attested the close relationship between internalization and OL. This result is in accordance with the empirical study of Al-adaileh et al. (2012) within Algerian context and the research of Ramírez et al., (2011) in Spain context. As advocated by Nonaka and Takeuchi (1995), internalization is an active process of learning by doing. According to Yoon et al. (2009), this mode of knowledge creation initiates fundamental organizational changes.

Finally, our findings confirm the importance of OL for innovation performance. This is in accordance with previous researches (Ramírez et al., 2011; Ramirez and Kumpikaite, 2012). In this line, Nonaka and Takeuchi (1995) stressed that OL process largely explains the innovative capacity of companies. Berraies (2012) pointed out also that organizational learning is among the most important key factors that contribute to innovation. In today's turbulent environment, organizations should develop their capacity to adapt their strategies in response to the environment's changes. This adaptability is based on the implementing within companies of an effective organizational learning process which permits in particular to meet customer needs and rapid technological changes.

On the basis of this study, a positive effect of KCP on innovation emerges both directly as well as indirectly via OL. Especially, we identified the importance of tacit-linked activities namely socialization, internalization and externalization for OL within the Tunisian ICT companies.

The contributions of this paper are theoretical as well managerial.

Our study contributes to the theoretical researches on the field of KCP, OL and innovation performance by building an integrative model that highlights the relationships between these variables. Through a literature review, we have considered the integration of a mediating variable as a variable optimizing link between KCP and innovation performance. In this line, we emphasized the role of OL as a mediator between these variables. Moreover, this research highlighted the most crucial dimensions of the SECI model in contributing to innovation and the development of OL. We further demonstrated the importance of the SECI model established by Nonaka et al. (1994) as an essence for firms' innovation in a totally different context than the Japanese context, namely the Tunisian context.

From a practitioner standpoint, this paper provides an opportunity for managers to better recognize the key factors for firm's innovation performance, namely KCP and OL. Indeed, on the basis of this research, managers have to devote efforts in order to improve KCP through reinforcing the socialization, externalization, combination and internalization processes and to boost effective organizational learning within companies.

Despite the contributions of this research, it nevertheless has limitations that should be highlighted and which offer perspectives for further researches. This study focused only on 
ICT companies. It would be thus interesting to extend the field of this research to other sectors especially the industrial sector. In addition, an empirical study on a larger sample would increase the likelihood of generalization of results. Moreover, we demonstrated in this paper the partial mediating effect of OL between KCP and innovation performance. Thus, OL is not the only mediator variable in this link. Other mediating and/or moderators variables could be integrated into our research model especially organizational trust and the age or the size of companies. A comparative cultural study could be interesting, especially between Arab cultural and Japanese culture on the basis of which the SECI model was conceptualized. Finally, it is also interesting to realize a mix of quantitative and qualitative empirical approach in order to explore in depth the relationship between KCP, OL and firm's innovation performance.

\section{References}

Afuah, A. (1998). Innovation Management: Strategies, Implementation, and Profits. Oxford University Press (Eds.), New York.

Al-adaileh, R.M., Dahou, K., \& Hacini, I. (2012). The Impact of Knowledge Conversion Processes on Implementing a Learning Organization Strategy. The Learning Organization. 19 (6), 482-496. http://dx.doi.org/10.1108/09696471211266947

Argyris, C., \& Schön, D. (1978). Organizational Learning: A Theory of Action Perspective. Addison Wesley, New York.

Baker, W.E., \& Sinkula, J.M. (1999). The Synergistic Effect of Market Orientation and Learning Orientation. Journal of the Academy of Marketing Science. 27 (4), 411-427.

Baron, R.M., \& Kenny, D.A. (1986). The Moderator-Mediator Variable Distinction in Social Psychological Research: Conceptual, Strategic, and Statistical Considerations. Journal of $\begin{array}{llrl}\text { Penality and Social } & \text { Psychology. } & \text { 51(6), }\end{array}$ http://dx.doi.org/10.1037/0022-3514.51.6.1173

Berraies, S. (2012). Le Rôle de la Gestion des Connaissances dans le Développement de l'Innovation. PhD Thesis, Higher Institute of Management of Tunis, Tunisia.

Binbin, Z., Jiangstao, D., Mingxing, L., \& Tongjian, Z., (2012). The Empirical Research on Independent Technology Innovation. Knowledge Transformation and Entreprise Growth RISUS. 3 (2), 19-26.

Bootz, J.P. (2001). Prospective et Apprentissage Organisationnel. Travaux et Recherche de Prospective, Futuribles International. 13.

Chin, W.W., \& Todd, P.A. (1995). On the Use, Usefulness, and Ease of Use of Structural Equation Modeling in MIS Research: A Note of Caution. MIS Quarterly. 19 (2), 237-246. http://dx.doi.org/10.2307/249690

Cohendet, P., Creplet, F., \& Dupouet, O. (2003). Innovation Organisationnelle, Communautés de Pratique et Communautés Epistémiques : le cas de Linux. Revue Française de Gestion. 29 (146), 99-121. http://dx.doi.org/10.3166/rfg.146.99-121

Colombelli, A., Krafft, J., \& Quatraro, F. (2013). Properties of Knowledge Base and Firm Survival: Evidence from a sample of French Manufacturing Firms. Technological Forecasting and Social Change: An international Journal. 80 (8), 1469-1483, DOI: 10.1016/j.techfore.2013.03.003 
Costanzo, L.A., \& Tzoumpa, V. (2008). Enhancing Organizational Learning in Teams: has the Middle Manager got a role?. Team Performance Management. 14(3/4), 146-164. http://dx.doi.org/10.1108/13527590810883424

Cummings, J., \& Kiesler, S. (2003). Coordination and Success in Multidisciplinary Scientific Collaborations. Proceedings of the 24th International Conference on Information Systems (ICIS), Seattle, Washington, USA.

Cyert, R.M., \& March, J.G. (1992). A Behavioral Theory of the Firm. Wiley-Blackwell, (2nd Eds), New Jersey, USA.

Damanpour, F. (1996). Organizational Complexity and Innovation: Developing and Testing Multiple Contingency Models. Management Science. 42(5), 693-713.

http://dx.doi.org/10.1287/mnsc.42.5.693

Dermol, V. (2013). Relationship between Learning, Knowledge Creation and Organisational Performance. Scientific Annals of the "Alexandru Ioan Cuza" University of Iaşi, Economic Sciences, 60 (1), 1-15 http://dx.doi.org/10.2478/aicue-2013-0008

Drucker, P.F. (1985). Innovation and Entrepreneurship: Practice and Principle. Harper \& Row (Eds), New York.

Fillol, C. (2006). Apprentissage Organisationnel et Contexte Organisationnel: Une Etude de Cas chez EDF. Proceedings of the XVth International Conference of Strategic Management, Annecy.

Fornell, C., \& Larker, D.F. (1981). Evaluating Structural Equations Models with Unobservable Variables and Measurement Error. Journal of Marketing Research. 18 (1), 39-50. http://dx.doi.org/10.2307/3151312

Garcia-Morales, V.J., Matias-Reche, F., \& Hurtado-Torres, N. (2008). Influence of Transformational Leadership on Organizational Innovation and Performance Depending on the Level of Organizational Learning in the Pharmaceutical Sector. Journal of Organizational Change Management. 21 (2), 188-212. http://dx.doi.org/10.1108/09534810810856435

Glisby, M., \& Holden, N. (2003). Contextual Constraints in Knowledge Management Theory: The Cultural Eembeddedness of Nonaka's Knowledge Creating Company. Knowledge and Process Management. 10 (1), 29-36. http://dx.doi.org/10.1002/kpm.158

Hair, J.F., Anderson, R.E., Tatham, R.L., \& Black, W.C. (1998). Multivariate Data Analysis. Prentice Hall ( $7^{\text {th }}$ Eds), New Jersey, USA.

Hall, R., \& Andriani, P. (2003). Managing knowledge associated with innovation. Journal of Business Research. 56, 145-152. http://dx.doi.org/10.1016/S0148-2963(01)00287-9

Hong, J. (2010). Nonaka's Knowledge Creation Model: Universal or Particularistic?. Proceedings of the International Conference on Organizational Learning, Knowledge and Capabilities (OLKC), Boston, US.

Huber, G.P. (1991). Organizational Learning: the Contributing Processes and a Review of the Literature, Organization Science, 2 (1), 88-117.

Hu, L.T., \& Bentler, P.M. (1999). Cutoff Criteria for Fit Indexes in Covariance Structure Analysis: Conventional Criteria versus New Alternatives. Structural Equation Modeling. 6(1), 1-55. http://dx.doi.org/10.1080/10705519909540118

Hutchings, K., \& Weir D. (2005). Cultural Embeddedness and Contextual Constraints: Knowledge Sharing in Chinese and Arab Cultures. Knowledge and Process Management. 
12(2), 89-98. http://dx.doi.org/10.1002/kpm.222

Jiménez-Jiménez, D., \& Sanz-Valle, R. (2011). Innovation, Organizational Learning and Performance. Journal of Business Research, 64 (4), 408-417. http://dx.doi.org/10.1016/j.jbusres.2010.09.010

Kluge, J., Stein, W., \& Licht, T. (2001), Knowledge Unplugged, Palgrave (1 ${ }^{\text {st }}$ Eds.), New York, USA. http://dx.doi.org/10.1057/9780333977057.

Levitt, B., \& March, J.G. (1988). Organizational Learning, Annual Review of Sociology, 14 (1988), 319-340. http://dx.doi.org/10.1146/annurev.so.14.080188.001535

Lundvall, B-Å. (1992), National Systems of Innovation: Towards a Theory of Innovation and Interactive Learning, Pinter Publishers, London.

Lyles, M.A.. (2014). Organizational Learning, Knowledge Creation, Problem Formulation and Innovation in Messy Problems. European Management Journal. 32(1), 132-136. http://dx.doi.org/10.1016/j.emj.2013.05.003

MacKinnon, D.P., Warsi, G., \& Dwyer, J.H. (1995). A Simulation Study of Mediated Effect Measures. Multivariate Behavioral Research. $30 \quad$ (1), 41-62. http://dx.doi.org/10.1207/s15327906mbr3001_3

Malerba, F.(1992). Learning by Firms and Incremental Technical Change. Economic Journal. 102 (413), 845-859. http://dx.doi.org/10.2307/2234581

March, J., \& Olsen, J. (1976). Organizational learning and the ambiguity of the past, In J. March and J. Olsen (eds), Ambiguity and choice in organizations (pp.54-68). Universitesforlaget, Bergen.

Miller, W.L., \& Morris, L. (1999). Fourth Generation R\&D: Managing Knowledge, Technology and innovation. John Wiley \& Sons ( $1^{\text {st }}$ Eds.), New York.

Nonaka, I. (1991). The Knowledge-creating Company. Harvard Business Review, 69 (6), 96-104.

Nonaka, I., \& Takeuchi, H. (1995). The Knowledge-creating Company. Oxford University Press (Eds.), New York.

Nonaka, I., Byosiere, P, Borucki, C., \& Konnot, N. (1994). Organizational Knowledge Creation Theory: A First Comprehensive Test. International Business Review, 3 (4), 337-351. http://dx.doi.org/10.1016/0969-5931(94)90027-2

Nonaka, I., Toyama, R., \& Konno, N. (2000). SECI, Ba and Leadership: A Unified Model of Dynamic Knowledge Creation. Long Range Planning. 33(1), 5-34. http://dx.doi.org/10.1016/S0024-6301(99)00115-6

Nonaka, I., Von Krogh, G., \& Voelpel, S. (2006). Organizational Knowledge Creation Theory: Evolutionary Paths and Future Advances. Organization Studies. 27 (8), 1179-1208. http://dx.doi.org/10.1177/0170840606066312

Popadiuk, S., \& Choo, C.W. (2006). Innovation and Knowledge Creation: How are These Concepts Related ?. International Journal of Information Management. 26 (4), 302-312. http://dx.doi.org/10.1016/j.ijinfomgt.2006.03.011

Porter, M. (1986). L'avantage concurrentiel. InterEdition, Paris.

Ramírez, A., Morales, V., \& Rojas, R. (2011). Knowledge Creation, Organizational Learning and their Effects on Organizational Performance. Engineering Economics. 22(3), 309-318. http://dx.doi.org/10.5755/j01.ee.22.3.521 
Ramirez, A.M., \& Kumpikaite, V. (2012). Creation, Transfer and Application of Knowledge and its Importance for Business Innovation and Organizational Performance. International Proceedings of Economics Development \& Research. 46 (6), 27-31.

Refaey, M. (2002). Knowledge Management: Evaluating the Role of Socialization, Externalization, Internalization and Combination Processes and its Effect on the Innovation Process: A Field Study on the Pharmaceutical Sector in Egypt. Commercial Studies \& Researches Journal. Faculty of Commerce-Banha (Egypt), 1 (1), 30-53.

Roussel, P., Durrieu, F., Campoy, E., \& El Akremi, A., (2002). Méthodes d'Equations Structurelles: Recherches et Application en Gestion. Economica, Paris.

Sankowska, A. (2013). Relationships Between Organizational Trust, Knowledge Transfer, Knowledge Creation and Firm's Innovativeness. Learning Organization. 20 (1), 85-100. http://dx.doi.org/10.1108/09696471311288546

Schulze, A., \& Hoegl, M. (2008). Organizational Knowledge Creation and the Generation of New Product Ideas: A behavioral approach. Research Policy. 37 (10), 1742-1750. http://dx.doi.org/10.1016/j.respol.2008.07.002

Škerlavaj, M., Song, J. H., \& Lee, Y. (2010). Organizational Learning Culture, Innovative Culture and Innovations in South Korean firms. Expert Systems with Applications, 37(9), 6390-6403. doi: 10.1016/j.eswa.2010.02.080

Sveiby, K.E. (1997). Knowledge management : La nouvelle richesse des entreprises, savoir tirer profit des actifs des entreprises. Maxima, Paris.

Svetina, A., \& Prodan, I. (2008). How Internal and External Sources of Knowledge Contribute to Firms' Innovation Performance. Managing Global Transitions. 6 (3), 277-299.

Tohidi, H., Seyedaliakbar, S.M., \& Mandegari, M. (2012). Organizational Learning Measurement and the Effect on Firm Innovation. Journal of Enterprise Information Management. 25 (3), 219-245. http://dx.doi.org/10.1108/17410391211224390

Van Der Bent, J., Paauwe, J., \& Williams, R. (1999). Organizational Learning: An Exploration of Organizational Memory and its Role in Organizational Change Processes. Journal of Organizational Change Management. 12(5), 377-404.

http://dx.doi.org/10.1108/09534819910289084

Wang, Z., \& Wang, N. (2012). Knowledge Sharing, Innovation and Firm Performance. Expert Systems with Applications. 39 (10), 8899-8908. http://dx.doi.org/10.1016/j.eswa.2012.02.017

Yoon, S. W., Song, J. H., \& Lim, D. H. (2009). Beyond the Learning Process and toward the Knowledge Creation Process: Linking Learning and Knowledge in the Supportive Learning Culture. Performance Improvement, Quarterly, 22 (3), 49-69. http://dx.doi.org/10.1002/piq.20060

Zohoori, M. Mohseni, S., Samadi, B., \& Attarnezhad, O. (2013), Journal of Small Business and Entrepreneurship Development. 1(1), 26-33.

\section{Glossary}

- ICT: Information and Communication Technology.

- KCP: Knowledge Creation Process.

- OL: Organizational Learning

- SECI: Socialization, Externalization, Combination, Internalization. 
$\mathrm{H} 4$

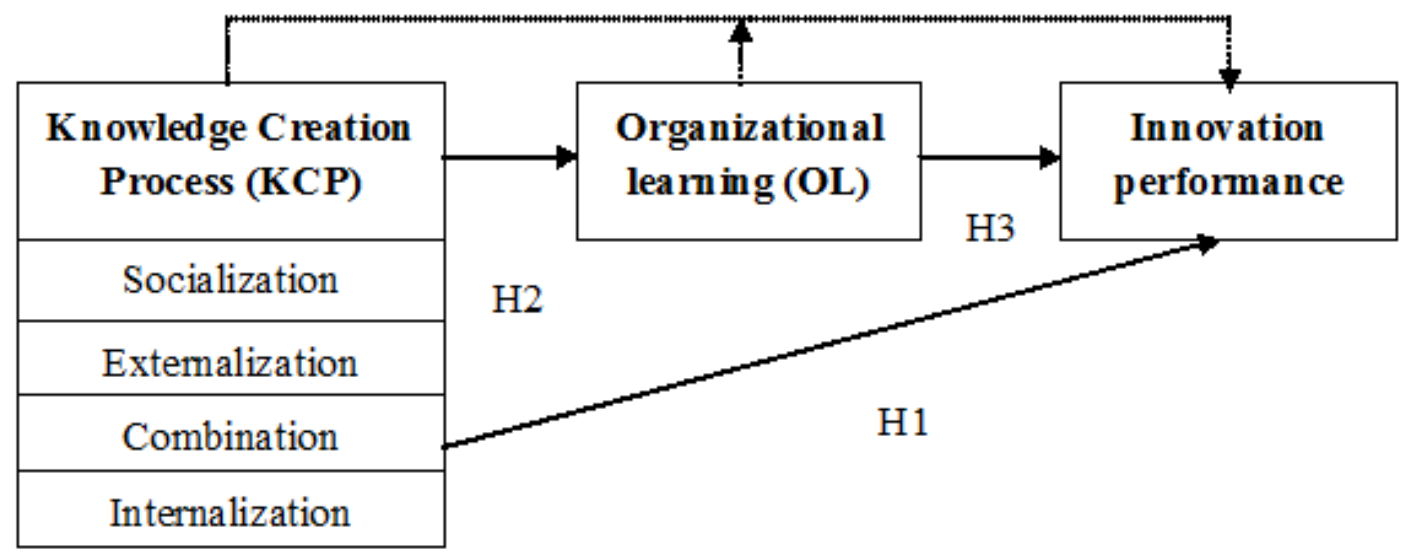

$\longrightarrow$ Direct link

$\rightarrow$ Indirect link

Figure 1. Research model

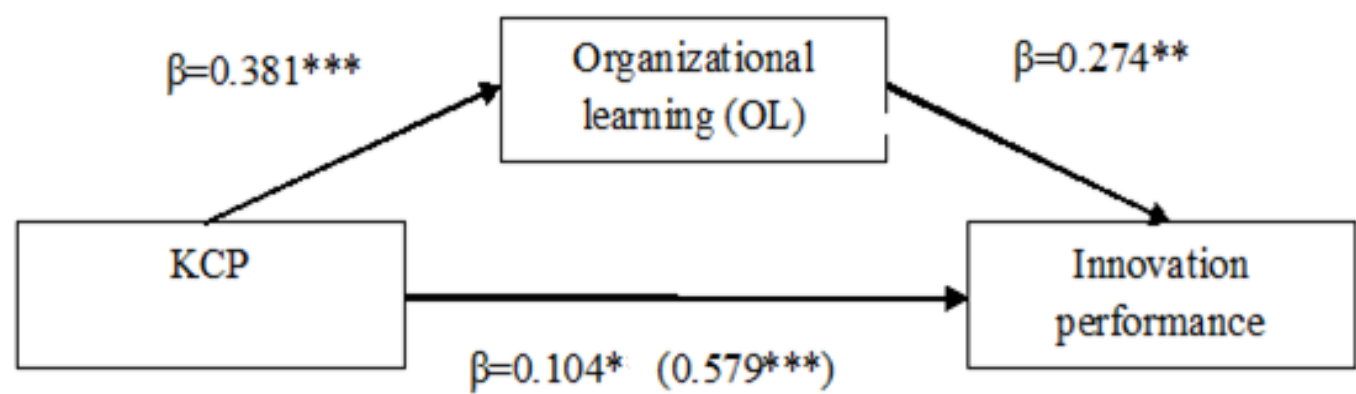

***: significant at the 0.001 level, *significant at the 0.05 level $\beta=$ standardised estimate

Figure 2. Research results 
Table 1. Reliability and convergent validity of measures' instruments

\begin{tabular}{|l|c|c|c|c|}
\hline \multicolumn{1}{|c|}{ Variables } & $\begin{array}{c}\text { Number of } \\
\text { items }\end{array}$ & $\begin{array}{c}\text { Cronbach's } \\
\text { Alpha }\end{array}$ & $\begin{array}{c}\text { Jôreskog's } \\
\text { Rhôs }\end{array}$ & pvc \\
\hline Socialization & 4 & 0.794 & 0.810 & 0.523 \\
\hline Externalization & 3 & 0.990 & 0.994 & 0.971 \\
\hline Combination & 3 & 0.728 & 0.754 & 0.519 \\
\hline Internalization & 3 & 0.781 & 0.785 & 0.551 \\
\hline Innovation performance & 4 & 0.887 & 0.890 & 0.778 \\
\hline OL & 8 & 0.723 & 0.719 & 0.503 \\
\hline
\end{tabular}

$\mathrm{vc}$ : Rhô of convergent validity

Table 2. Fit indices of model tested

\begin{tabular}{|c|c|c|c|c|c|}
\hline Fit indices & $\square \mathbf{2}$ /ddl & GFI & RMSEA & CFI & NFI \\
\hline Level of acceptation & $\leq 3$ & $>0,90$ & $<0,08$ & $>0,95$ & $>0,9$ \\
\hline Model tested & 2.094 & 0.926 & 0.062 & 0.987 & 0.966 \\
\hline
\end{tabular}

$\chi 2 / \mathrm{df}=$ Chi-Square value/degrees of freedom, GFI: Goodness-of-fit index, CFI: Comparative Fit Index, RMSEA= Root Mean Square Error of Approximation, Normed Fit Index

Table 3. Results of Model tested

\begin{tabular}{|l|c|c|c|c|}
\hline $\begin{array}{l}\text { Independent } \\
\text { variable }\end{array}$ & Dependant variable & Standardized estimate & C.R. & P \\
\hline KCP & Innovation performance & $\beta=0.579$ & 5.223 & $* * *$ \\
\hline KCP & OL & $\beta=0.381$ & 4.137 & $* * *$ \\
\hline OL & Innovation performance & $\beta=0.274$ & 3.524 & $* * *$ \\
\hline
\end{tabular}

C.R.: Critical Ratio, P: level of acceptance, ***: significant at the 0.001 level 